\title{
OPTIMIZATION OF CONTROLLED EXPLOSION PROCESSES PARAMETERS USING COMPLEX ANALYSIS METHODS
}

\author{
Andrii Ya. Bomba ${ }^{1}$, Andrii P. Safonyk ${ }^{2}$, Kateryna M. Malash ${ }^{1}$ \\ ${ }^{1}$ Rivne State Humanitarian University, Mathematics and Informatics Faculty \\ ${ }^{2}$ National University of Water and Environmental Engineering, Institute of Automation, Cybernetics and Computer Engineering
}

Abstract. The optimal charge power and position necessary for forming the maximum possible size of the crater along with preservation of the integrity of the two nearby objects with the numerical quasiconformal mapping methods with the alternate parameterization of the of the medium and process character are established. Unambiguously the boundaries of crater, pressed and disturbed soil zones are identified and the corresponding field dynamic grid is built. A number of experiments was held on the basis of the developed algorithm and their results were analyzed.

Keywords: explosion processes, mathematical modelling, parameters identification, quasiconformal mappings

\section{OPTYMALIZACJA PARAMETRÓW KONTROLOWANYCH PROCESÓW WYBUCHU PRZY UŻYCIU ZLOŻONYCH METOD ANALITYCZNYCH}

Streszczenie. Optymalna siła wybuchu i położenie ładunku niezbędne do utworzenia maksymalnego rozmiaru uderzenia, o ile zachowana jest integralność dwóch sąsiednich obiektów, sa ustalane za pomoca metod odwzorowań quasikonowych z naprzemienna parametryzacja właściwości medium i procesu. Równocześnie ustala się granice dziury, wciśniętych i niezabezpieczonych części ośrodka oraz konstruuje dynamiczna siatke pola. Na podstawie opracowanego algorytmu przeprowadzono eksperymenty numeryczne i zanalizowano ich wyniki.

Slowa kluczowe: identyfikacja, modelowanie matematyczne, procesy wybuchowe, quasi-konformacyjne odwzorowania

\section{Introduction}

The upper layers of the earth's crust are increasingly exploited in industry, building construction, and infrastructure at the present stage of society's development. There are many semi-underground and completely underground structures such as shopping malls, parking lots, low floors of high-rise buildings. Also, the number of underground transport routes is growing rapidly. Practically all metropolises successfully operate the subway, a number of long underground tunnels even under water are created. There are the Euro-tunnel under the La-Mansh Channel, the under-Bosphorus tunnel in Istanbul exist, the construction of an underground tunnel between Germany and Denmark is planned, and even one of the Hyperloop routes will use an underground tunnel. The minerals extraction "deepens" under the ground more and more, since easily accessible deposits are already largely exhausted.

The formation of large cavities in the upper layers of the crust plays a very important role in carrying out all of the abovementioned works. One of the ways of their formation is the using of explosive processes. It allows you to get the desired result for a rather short period of time and significantly less cost (in comparison, for example, with high-costing drilling). Also, the problem of eliminating excavated soil is automatically eliminated and the problem of strengthening the walls of the formed cavities is solved, as a result of the explosion around the fissure, a pressed zone is formed.

However, the using of an explosion processes requires a clear pre-determination of the necessary parameters, because minor errors can lead to catastrophic consequences. This is especially needed when near the locations where explosive processes are used, there are certain objects situated, such as residential buildings.

Various mathematical models are used by different scientists to investigate explosive processes, the most common of which are solid, solid-liquid and liquid ones [2, 8, 11, 12, 15]. The model used in this article is based on the liquid one and is implemented with using the quasi-conformal mappings methods and a step-by-step parameterization of the medium and process characteristics $[1,13]$.

\section{Problem statement}

We solve the following problem. In the environment where the explosion should occur, there are some two points $\mathrm{M}$ and $\mathrm{N}$, between which it is necessary to create a the crater of the maximum size so that these points are in the unperturbed zone. The form and size of charge are also known a priori. It is necessary to determine the explosive power of charge and location of its position, as well as the boundaries of the sections of the crater, pressed and unperturbed parts of the environment, resulting from the explosion (Fig. 1).

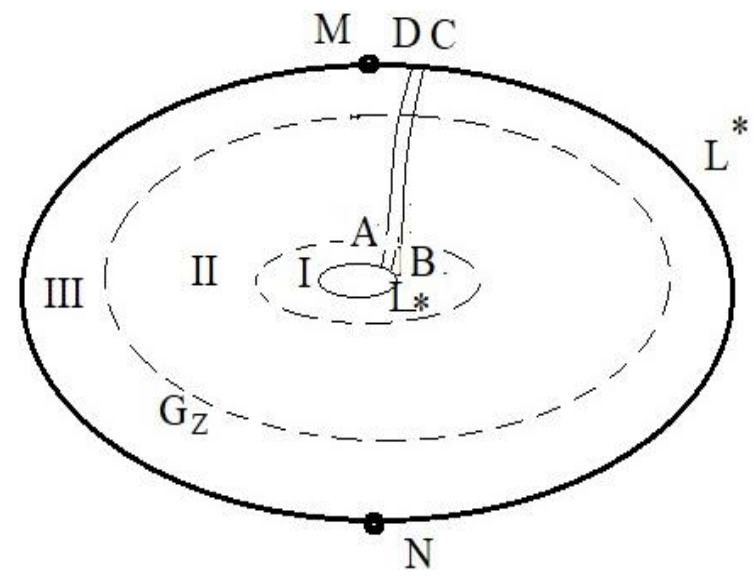

Fig. 1. Schematical physical domain

The idea of solving the problem is as follows. Some initial domain $G_{z} \quad(z=x+i y)$ is determined. The charge is placed so that it is evenly spaced from the points $\mathrm{M}$ and $\mathrm{N}$ at a minimum distance from them. The charge contour is known a priori: $L_{*}=\left\{z: f_{*}(x, y)=0\right\}=\left\{x+i y: x=x_{*}(t), y=y_{*}(t), \alpha_{*}<t<\beta_{*}\right\}$.

We set the $\left.\varphi\right|_{L *}=\varphi_{*}=0,\left.\varphi\right|_{L_{s}^{*}}=\varphi^{*}=\varphi_{0}^{*},-\infty<\varphi_{*}<\varphi_{0}^{*}<+\infty$. The boundary values of potentials are set so that they do not differ significantly. 
The process of particles motion of the medium will be described using the equation of motion $\vec{v}=k \operatorname{grad} \varphi$ and the equation of continuity $\operatorname{div} \vec{v}=0$, where $\vec{v}=\left(v_{x}(x, y), v_{y}(x, y)\right)$ is the particle velocity, $\varphi=\varphi(x, y)$ is the quasipotential of the corresponding field, $k=k(\mid \operatorname{grad} \varphi) \mid)=k(I)$ is the permeability coefficient of the medium (which characterizes the ability of particles to rise) [4,6]. Also, we take into account the inverse effect of the process characteristics on the characteristics of the environment, so in the process of solving the problem, the coefficient $k$ is specified:

$$
k=k_{0}+\frac{1}{2} \beta\left(I-I^{*}\right)\left(\left(I-I^{0}\right)+\left|I-I^{0}\right|\right)
$$

here $I=\sqrt{\varphi_{x}^{2}+\varphi_{y}^{2}}, I^{0}, I^{*}$ are the critical values of the gradient, which characterize the delay and particle separation (the position of the line of the section), the parameter characterizing the change in permeability of the medium, is selected on the basis of the physical experiment [4]. The outer contour $L_{s}^{*}=\left\{z: f^{*}(x, y)=0\right\}$ $=\left\{x+i y: x=x_{s}^{*}(t), \quad y=y_{s}^{*}(t), \quad \alpha^{*}<t<\beta^{*}\right\} \quad$ of the initial domain is defined as described in [5].

Let's solve the problem using the quasiconformal mappings methods [3, 7]. We introduce the function $\psi=\psi(x, y)$ complex conjugate to $\varphi=\varphi(x, y)$ and form a conditional section of the domain $G_{z}$ along one of the flow lines (as shown in Fig. 1). We obtain the problem of a quasiconformal mapping $\omega=\omega(z)=\varphi(x, y)+\mathrm{i} \psi(x, y)$ of the formed single-connected domain $G_{z}^{0}$ to an appropriate rectangular area of the quasicomplex potential $G_{\omega}=\left\{\omega=\varphi+i \psi: \varphi_{*}<\varphi<\varphi^{*}, 0<\psi<Q\right\} \quad$ with an unknown parameter $Q$.

$$
\begin{gathered}
\kappa(\mid \operatorname{grad} \varphi) \mid) \frac{\partial \varphi}{\partial x}=\frac{\partial \psi}{\partial y}, \\
\kappa(\mid \operatorname{grad} \varphi) \mid) \frac{\partial \varphi}{\partial y}=-\frac{\partial \psi}{\partial x},(x, y) \in G_{z}^{0}, \\
\left.\varphi\right|_{L_{*}}=\varphi_{*},\left.\quad \varphi\right|_{L_{s}^{*}}=\varphi_{0}^{*},\left.\quad \psi\right|_{A D}=0, \\
\left.\psi\right|_{B C}=Q=\oint_{L_{*}}-v_{y} d x+v_{x} d y
\end{gathered}
$$

\section{The inverse problem statement}

We turn to the inverse problem on the quasi-conformal mapping $z=z(\omega)=x(\varphi, \psi)+i y(\varphi, \psi)$ quasiconformal potential domain $G_{\omega}$ to the physical domain $G_{z}^{0}$ for finding the real $x=x(\varphi, \psi)$ and imaginary $y=y(\varphi, \psi)$ parts of the characteristic function equation of the flow line with unknown partition lines and the unknown value of the parameter $Q$ :

$$
\begin{gathered}
\kappa\left(\frac{1}{J} \sqrt{\left(\frac{\partial x}{\partial \psi}\right)^{2}+\left(\frac{\partial y}{\partial \psi}\right)^{2}}\right) \frac{\partial y}{\partial \psi}=\frac{\partial x}{\partial \varphi}, \\
\kappa\left(\left(\frac{1}{J} \sqrt{\left(\frac{\partial x}{\partial \psi}\right)^{2}+\left(\frac{\partial y}{\partial \psi}\right)^{2}}\right) \frac{\partial x}{\partial \psi}=-\frac{\partial y}{\partial \varphi},\right. \\
(\varphi, \psi) \in G_{\omega}, \quad J=x_{\varphi} y_{\psi}-x_{\psi} y_{\varphi}, \\
f_{*}\left(x\left(\varphi_{*}, \psi\right), y\left(\varphi_{*}, \psi\right)\right)=0, \quad \varphi_{*} \leq \varphi \leq \varphi_{0}{ }^{*}, \\
f_{s}^{*}\left(x\left(\varphi_{0}{ }^{*}, \psi\right), y\left(\varphi_{0}{ }^{*}, \psi\right)\right)=0, \quad 0 \leq \psi \leq Q, \\
x(\varphi, 0)=x(\varphi, Q), \quad y(\varphi, 0)=y(\varphi, Q), \quad \varphi_{*}<\varphi<\varphi_{0}{ }^{*},
\end{gathered}
$$

We arrive at the Laplace type equations:

$$
\begin{aligned}
& \frac{\partial}{\partial \varphi}\left(\frac{1}{\kappa} \frac{\partial x}{\partial \varphi}\right)+\frac{\partial}{\partial \psi}\left(\kappa \frac{\partial x}{\partial \psi}\right)=0 . \\
& \frac{\partial}{\partial \varphi}\left(\frac{1}{\kappa} \frac{\partial y}{\partial \varphi}\right)+\frac{\partial}{\partial \psi}\left(\kappa \frac{\partial y}{\partial \psi}\right)=0 .
\end{aligned}
$$

\section{The numerical algorithm of problem solving}

The algorithm for numerical solving the problem is constructed as described, for example, in [3]. The difference analogs of equations (6), boundary conditions (4), as well as additional conditions for boundary and near-boundary nodes in the corresponding uniform grid:

$G_{\omega}^{\gamma}=\left\{\left(\varphi_{i}, \psi_{j}\right): \varphi_{i}=\varphi_{*}+i \cdot \Delta \varphi, i=\overline{0, n} ; \psi_{j}=j \cdot \Delta \psi, j=\overline{0, m} ;\right.$

$\left.\Delta \varphi=\frac{\varphi^{*}-\varphi_{*}}{n}, \Delta \psi=\frac{Q}{m}, \gamma=\frac{\Delta \psi}{\Delta \varphi}\right\}$

will be written in the following form:

$$
\left\{\begin{array}{l}
\sigma\left(a_{i+1, j+1} x_{i+1, j+1}-\left(a_{i+1, j+1}+a_{i, j+1}\right) x_{i, j+1}+a_{i, j+1} x_{i-1, j+1}\right)+ \\
+(1-2 \sigma)\left(a_{i+1, j} x_{i+1, j}-\left(a_{i+1, j}+a_{i, j}\right) x_{i, j}+a_{i, j} x_{i-1, j}\right)+ \\
+\sigma\left(a_{i+1, j-1} x_{i+1, j-1}-\left(a_{i+1, j-1}+a_{i, j-1}\right) x_{i, j-1}+a_{i, j-1} x_{i-1, j-1}\right)+ \\
+\gamma^{2}\left(\sigma\left(b_{i+1, j+1} x_{i+1, j+1}-\left(b_{i+1, j+1}+b_{i+1, j}\right) x_{i+1, j}+b_{i+1, j} x_{i+1, j-1}\right)+\right. \\
+(1-2 \sigma)\left(b_{i, j+1} x_{i, j+1}-\left(b_{i, j+1}+b_{i, j}\right) x_{i, j}+b_{i, j} x_{i, j-1}\right)+ \\
\left.+\sigma\left(b_{i-1, j+1} x_{i-1, j+1}-\left(b_{i-1, j+1}+b_{i-1, j}\right) x_{i-1, j}+b_{i-1, j} x_{i-1, j-1}\right)\right)=0, \\
\sigma\left(a_{i+1, j+1} y_{i+1, j+1}-\left(a_{i+1, j+1}+a_{i, j+1}\right) y_{i, j+1}+a_{i, j+1} y_{i-1, j+1}\right)+ \\
+(1-2 \sigma)\left(a_{i+1, j} y_{i+1, j}-\left(a_{i+1, j}+a_{i, j}\right) y_{i, j}+a_{i, j} y_{i-1, j}\right)+ \\
+\sigma\left(a_{i+1, j-1} y_{i+1, j-1}-\left(a_{i+1, j-1}+a_{i, j-1}\right) y_{i, j-1}+a_{i, j-1} y_{i-1, j-1}\right)+ \\
+\gamma^{2}\left(\sigma\left(b_{i+1, j+1} y_{i+1, j+1}-\left(b_{i+1, j+1}+b_{i+1, j}\right) y_{i+1, j}+b_{i+1, j} y_{i+1, j-1}\right)+\right. \\
+(1-2 \sigma)\left(b_{i, j+1} y_{i, j+1}-\left(b_{i, j+1}+b_{i, j}\right) y_{i, j}+b_{i, j} y_{i, j-1}\right)+ \\
\left.+\sigma\left(b_{i-1, j+1} y_{i-1, j+1}-\left(b_{i-1, j+1}+b_{i-1, j}\right) y_{i-1, j}+b_{i-1, j} y_{i-1, j-1}\right)\right)=0, \\
i=\overline{1, n}, \quad j=\overline{1, m .}
\end{array}\right.
$$

Here

$$
\begin{gathered}
a_{i, j}=\frac{\kappa_{i, j}+\kappa_{i-1, j}}{2 \kappa_{i, j} \kappa_{i-1, j}}, \quad b_{i, j}=\frac{\kappa_{i, j}+\kappa_{i, j-1}}{2}, \\
k_{i, j}=k_{0}+\frac{1}{2} \beta\left(I_{i, j}-I^{*}\right)\left(\left(I_{i, j}-I^{0}\right)+\left|I_{i, j}-I^{0}\right|\right), \\
I_{i, j}=\frac{2 \Delta \varphi}{J_{i, j}} \sqrt{\left(x_{i, j+1}-x_{i, j-1}\right)^{2}+\left(y_{i, j+1}-y_{i, j-1}\right)^{2}} . \\
J_{i, j}=\left(x_{i+1, j}-x_{i-1, j}\right)\left(y_{i, j+1}-y_{i, j-1}\right)-\left(x_{i, j+1}-x_{i, j-1}\right)\left(y_{i+1, j}-y_{i-1, j}\right) \\
i=\overline{1, n}, \quad j=\overline{1, m} .
\end{gathered}
$$

We obtain the formula for the approximation of the quantity $\gamma$ on the basis of the quasi-conformal similarity in the small of the two domains [3]:

$$
\gamma=\frac{k_{i, j}}{(m+1)(n+1)} \sum_{i, j=0}^{m, n} \frac{\alpha_{i, j}+\alpha_{i, j+1}}{\alpha_{i, j}+\alpha_{i+1, j}},
$$

where

$$
\alpha_{i, j}=\sqrt{\left(x_{i+1, j}-x_{i, j}\right)^{2}+\left(y_{i+1, j}-y_{i, j}\right)^{2}} .
$$




$$
\begin{aligned}
& f_{*}\left(x_{0, j}, y_{0, j}\right)=0, \\
& f^{*}\left(x_{n, j}, y_{n, j}\right)=0, \\
& j=\overline{0, m} .
\end{aligned}
$$

To clarify the boundary and near-boundary nodes we use the following difference formulas:

$$
\begin{aligned}
& \left(\frac{\partial f^{*}}{\partial y}\right)_{n, j}\left(3 x_{n, j}+x_{n-2, j}-4 x_{n-1, j}\right)-\left(\frac{\partial f^{*}}{\partial x}\right)_{n, j}\left(3 y_{n, j}+\right. \\
& \left.+y_{n-2, j}-4 y_{n-1, j}\right)=0, \quad j=\overline{0, m}, \\
& \left(\frac{\partial f_{*}}{\partial y}\right)_{0, j}\left(4 x_{1, j}-3 x_{0, j}-x_{2, j}\right)-\left(\frac{\partial f_{*}}{\partial x}\right)_{0, j}\left(4 y_{1, j}-\right. \\
& \left.-3 y_{0, j}-y_{2, j}\right)=0, \quad j=\frac{\bar{m}}{2}, m,
\end{aligned}
$$
form:

The "gluing" conditions on a conditional cut have the such

$$
x_{i, 0}=x_{i, m}, y_{i, 0}=y_{i, m}, i=\overline{0, n},
$$

The numerical realization of developed algorithm is carried out, as described in $[4,5]$.

\section{Determination of explosive charge power}

We obtain the outer boundary contour $L_{s 1}^{*}$ of the initial domain $G_{z}$ and the boundaries of the crater section (depicts I on Fig. 1), the pressed (II) and unperturbed (III) sections of the soil as a result of numerical calculations for the initial domain We check the position of the $\mathrm{M}$ and $\mathrm{N}$ points relative to the contour $L_{s 1}^{*}$ according to the following algorithm:

1) If both points belong to the contour, then the problem is solved, and the potential value $\varphi_{0}^{*}$ is sought. However, the probability of such a coincidence is rather low.

2) If one of the points (e. g. N) belongs to the contour, then we determine the position relative to the contour of the other point (M). $\mathrm{f}$ it is placed inside the contour, we find the distance from it to the contour (let we denote it $l$ ), and return to the beginning of the task solution with the specified position of the charge contour $L_{*}$ by moving it towards point $\mathrm{N}$ at a distance of $l / 2$. In the case the point $\mathrm{M}$ is located outside the contour $L_{s 1}^{*}$, we specify the contour $L_{*}$ position by approaching it to the point $\mathrm{M}$ at a distance of $l / 2$ and solve the problem again. Repeat these steps until both sides $\mathrm{M}$ and $\mathrm{N}$ are not placed inside the contour $L_{s 1}^{*}$. In this case, the problem is solved, the identified charge positions, the boundaries of the crater section, the pressed and unperturbed sections of the soil are sought-after, and the value of the explosive charge force $\varphi_{0}^{*}$ is the desired magnitude.

3) If both the points $\mathrm{N}$ and $\mathrm{M}$ are placed inside the contour $L_{s 1}^{*}$, then we increase the value of $\varphi_{0}^{*}$ parameter to a certain value $\Delta \varphi 0<<\varphi_{0}^{*}$ and solve the problem with the specified value $\varphi_{0}^{*}$, after which we check the position of the points $\mathrm{M}$ and $\mathrm{N}$ relative to the external contour again. If they are still placed inside the contour, we repeat paragraph 3) until one of them (or both) is belong or placed outside of the contour. If the both points belong to the contour then the problem is solved. If the only one point belongs to the contour then we go to paragraph 2). If at least one of the points has gone beyond the contour, we reduce the value $\varphi_{0}^{*}$ by magnitude $\Delta \varphi 0=\Delta \varphi 0 / 2$ and solve the problem with the specified value of quasipotential again. Repeat this action until one of the points will belong to the contour. Then we move to paragraph 2).

4) If one of the points (e. g., N) is placed outside the contour, and the other one is placed inside, we reduce the value $\varphi_{0}^{*}$ by value $\Delta \varphi_{0}$ i and solve the problem with the specified quasipotential value again (similar to paragraph 3)) until one of the points belongs to the contour, and the other is placed inside. Then we move to paragraph 2).

\section{The numerical experiments results}

On the basis of the developed algorithm a number of numerical experiments have been carried out, which confirm the expediency of its use for solving such type of problems while the modelling of the impact of the explosive process on the medium.

Here are the results of numerical experiments for input data $n \times m=70 \times 100, I^{*}=0.008, I^{0}=0.004$,

$\left(f_{1}\right)=\left\{z: f_{*}(x, y)=0\right\}=\{x+i y: x=10+6 \cos (t), y=5+5 \sin (t)$, $0 \leq t<2 \pi\}, \varphi_{*}=0, \varphi_{0}{ }^{*}=0.1, \beta=0,05, \mathrm{M}=(0 ; 1), \mathrm{N}=(0 ;-1)$ (Fig. 2).

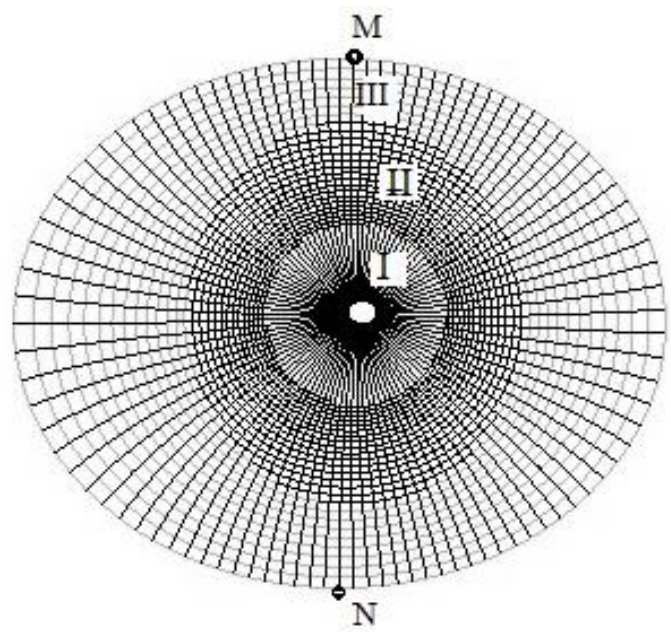

Fig. 2. The identified explosion results

\section{Conclusions}

A mathematical model of the explosion impact on the environment was developed using quasiconformal mappings numerical methods and a step-wise parametrization of the environment and process parameters taking into account their interaction. This model provides optimization of the explosive process parameters, namely allows to identify the position and explosive force of the charge of a given shape and size in order to create the maximum crater between the two given points. At the same time, the points themselves are placed in the unperturbed zone. At the same time, the boundaries of the crater section, the pressed and unperturben sections of the environment in which the explosion takes place are determined, and a dynamic grid of the field formed by it is constructed.

The developed algorithm allows to calculate the necessary parameters for carrying out of blasting works nearby important objects for reception of the maximum possible cavity without danger of their damage.

In the long run is optimization of the explosive process parameters to get the crater of the maximum possible size, provided that the integrity of three or more objects adjacent to each other is preserved; determining the optimal shape or size of the required charge; taking into account the possible anisotropy of the medium; the possibility and expediency of using two or more charges; corresponding spatial problems. 


\section{References}

[1] Blair D. E.: Inversion theory and conformal mapping, American Mathematical Society, 2000.

[2] Bomba A. Ya., Bulavatskii V. M., Skopetski V. V.: Nonlinear mathematical models of geohydrodynamics processes. Naukova dumka, Kiev 2007

[3] Bomba A. Ya., Kashtan S. S., Pryhornytskyi D. O., Yaroshchak S. V.: Complex analysis methods. Editorial and Publishing Department of NUWEE, Rivne 2013 (in Ukrainian).

[4] Bomba A. Ya., Malash K. M.: Modeling of the explosion process in an anisotropic medium with quasiconformal mapping methods. Transactions of Kremenchuk Mykhailo Ostrohradskyi National University, 4th (105th) ed., Kremenchuk, 2017, 28-33.

[5] Bomba A. Ya., Malash K. M.: Modeling of explosive processes in anisotropic media where boundary of the influence region is identified. Mathematical and computer modelling, serie "Technical sciences" 18, 2018, 3-16.

[6] Bomba A. Ya., Sinchuk A. M.: Using quasi-conformal mappings to mathematical modeling of explosion processes. Volynskii matematychnii visnyk, Serie "Applied mathematics" 8, 2011, 32-41.

[7] Bomba A. Ya., Skopetskii V. V., Prigornitskii D. O.: Numerical solution of nonlinear modeling boundary value problems on quasi-conformal mapping under conditions of interaction of gradients of potential and environmental characteristics. Visnyk Kiivskoho Universitetu, serie "Physics and mathematics" 1, 2003, 126-135

[8] Bulavatskii V. M., Kryvonos Yu. G., Skopetskii V. V.: Nonclassic mathematical models of heat- and mass transfer processes. Naukova Dumka, Kiev 2005.

[9] Bulavatskii V. M., Luchko I A.: Some inverse problems of the pulsedhydrodynamic theory of explosion on the discharge. Investigations on boundary value problems of hydrodynamics and thermophysics, Kiev 1979, 53-64.

[10] Ilinskii N. B., Potashev A. V.: Explosion Theory boundary problems. Izdatelstvo Kazanskogo universytetu, Kazan 1986.

[11] Korobijchuk V. V., Sobolevs'kyj R. V., Zubchenko A.: Investigation of ways to minimize the cost of drilling and blasting of blocks of decorative stone. Visnyk Zhytomyrs'kogo Derzhavnogo Tehnologichnogo Universytetu, serie "Tehnichal sciences" 4 (39), 2006, 301-308.

[12] Kravets V. G., Korobyichuk V. V., Boiko V. V.: Physical processes of applied geodynamics of an explosion: monograph. ZSTU, Zhytomyr 2015.

[13] Nearling J.: Mathematical tools for physics. Miami 2008.

[14] Prigornitskii D. O.: Modification of the algorithm for numerical solving a class of nonlinear modeling boundary value problems on quasi-conformal mappings in two-coupling deformable media. Volynskii matematychnii visnyk, serie "Applied mathematics" 9, 2002, 60-66.

[15] Vlasov O. E., Smyrnov S. A.: About explosion modelling. Explosion business. 59th ed, Nedra, Moskva 1966, 109-117.
D.Sc. Andrii Ya. Bomba

e-mail: abomba@ukr.net

The Head of Department of Informatics and Applied Mathematics of Rivne State Humanitarian University. $\mathrm{He}$ is the author of over 450 scientific works, including 9 monographs. A well-known specialist in mathematical modeling and computational methods. Academician of the UNGA. Member of four editions of collections of scientific works and two Specialized Scientific Councils for the defense of thesis.

ORCID ID: 0000-0001-5528-4192

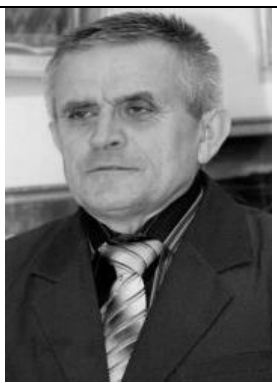

\section{D.Sc. Andrii Safonyk}

e-mail:safonik@ukr.net

Professor of the Department of automation, electrical engineering and computer integrated technologies of the Institute of Automation, Cybernetics and Computer Engineering, National University of Water and Environmental Engineering, Rivne, Ukraine.

Engaged in scientific mathematical modeling of natural and technological processes, computer techniques and computer technologies, programming.

ORCID ID: 0000-0002-5020-9051

M.Sc. Kateryna M. Malash

e-mail: katemalash@gmail.com

The Ph.D. student of Department of Informatics and Applied Mathematics of Rivne State Humanitarian University.

She is engaged in mathematical modelling of technological processes, specially explosions, particularly using the numerical quasiconformal mapping methods; also works with modern computer technologies and programming.

ORCID ID: 0000-0003-4771-9349

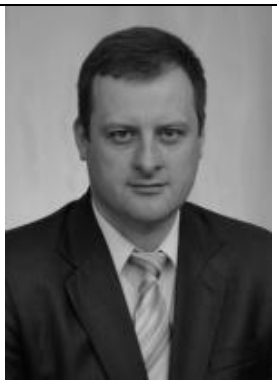

otrzymano/received: 20.02 .2019 przyjęto do druku/accepted: 11.03 .2019 